\title{
Como não nos tornamos professoras? ${ }^{1}$
}

\author{
Osvaldo Teodoro dos Santos Filho \\ Leandro Luciano Silva Ravnjak ${ }^{3}$ \\ Shirley Patrícia Nogueira de Castro e Almeida ${ }^{4}$
}

\begin{abstract}
Resumo: O presente trabalho foi escrito como requisito parcial de avaliação de uma disciplina do Programa de Pós-graduação em Educação numa universidade pública no Brasil. No primeiro momento fazemos algumas considerações com o objetivo de explicar porque não construímos um memorial, desse modo, enfatizamos a interseção entre a concepção neoliberal presente nas reformas educacionais e a ideologia pós-moderna na Formação de Professores. No momento seguinte, apresentamos, ainda que de forma introdutória, algumas notas sobre expressões comuns utilizadas pelos professores ao narrarem suas memórias e, na sequência, elencamos algumas trajetórias que acompanhamos em alguma medida durante parte do nosso processo formativo. Por fim, sublinhamos a necessidade de compreender a funcionalidade da ideologia, ocultando determinações, naturalizando processos históricos e, a partir de uma compreensão fragmentada da realidade, obstruindo ações organizativas que proporcionem saltos de qualidade aos trabalhadores.
\end{abstract}

Palavras-chave: Memorial. Formação de Professores. Ideologia.

\section{How do we not become teachers?}

Abstract: The present paper was written as a partial requirement for the evaluation of a discipline of the Graduate Program in Education at a public university in Brazil. At first, we make some considerations in order to explain why we did not build a memorial, thus, we emphasize the intersection between the neoliberal conception present in educational reforms and the post-modern ideology in Teacher Education. Next, we present, albeit in an introductory way, some notes on common expressions used by teachers when narrating their memories and, subsequently, we list some trajectories that we follow to some extent during part of our training process. Finally, we emphasize the need to understand the functionality of ideology, hiding determinations, naturalizing historical processes and,

\footnotetext{
${ }^{1} \mathrm{O}$ título do trabalho é uma alusão ao livro: Como nos tornamos professoras? de autoria de Roseli A. Cação Fontana (2000), estudado no decorrer da disciplina.

${ }^{2}$ Professor de História efetivo na Rede Estadual de Educação Básica de Minas Gerais. Minas Gerais, Brasil. E-mail: osvaldoteodoro2003@gmail.com. ORCID: https://orcid.org/0000-0003-4869-4411.

${ }^{3}$ Doutor em Educação. Docente Permanente do Programa de Pós-Graduação em Educação da Unimontes. Docente do Curso de Direito da UNIMONTES. Docente do Curso de Direito do Centro Universitário FIPMoc - UNIFIPMoc. Minas Gerais, Brasil. E-mail: leandro.silva@unimontes.br. ORCID: https://orcid.org/0000-0002-8903-6442.

${ }^{4}$ Doutora em Educação. Professora efetiva do Departamento de Métodos e Técnicas Educacionais e professora permanente do Programa de Pós-graduação em Educação (PPGE) da Universidade Estadual de Montes Claros. Minas Gerais, Brasil. E-mail: shirley.almeida@unimontes.br. ORCID: https://orcid.org/0000-0002-4785-7963.
} 
based on a fragmented understanding of reality, obstructing organizational actions that provide quality leaps for workers.

Keywords: Memorial. Teacher training. Ideology

\section{¿Cómo no nos convertimos en maestros?}

Resumen: El presente trabajo fue escrito como requisito parcial para la evaluación de una disciplina del Programa de Posgrado en Educación de una universidad pública de Brasil. En un primer momento, hacemos algunas consideraciones para explicar por qué no construimos un memorial, así, enfatizamos la intersección entre la concepción neoliberal presente en las reformas educativas y la ideología posmoderna en la Formación Docente. A continuación, presentamos, aunque de forma introductoria, algunas notas sobre expresiones comunes utilizadas por los docentes al narrar sus recuerdos y, posteriormente, enumeramos algunas trayectorias que seguimos en cierta medida durante parte de nuestro proceso formativo. Finalmente, destacamos la necesidad de comprender la funcionalidad de la ideología, ocultando determinaciones, naturalizando procesos históricos y, desde una comprensión fragmentada de la realidad, entorpeciendo acciones organizativas que brinden saltos de calidad para los trabajadores.

Palabras clave: Monumento. Formación de profesores. Ideología.

[...] absorvido pelos objetos concretos, não consegue perceber sua concatenação; preocupado com sua existência,

não atenta em sua origem nem em sua caducidade; obcecado pelas árvores, não consegue ver o bosque.

Friedrich Engels

\section{Introdução}

Fomos convidados, no decorrer de uma das disciplinas do Programa de Pósgraduação em Educação a construir, como requisito parcial de avaliação, um memorial. Este, tem se constituído, cada vez mais, como instrumento avaliativo nos cursos de graduação e de pós-graduação no Brasil ${ }^{5}$. De acordo com Oliveira (2005, p. 121), um memorial consiste em um "[...]documento escrito relativo à lembrança, à vivência de alguém; memórias. Deve conter um breve relato sobre a história de vida pessoal, profissional e cultural do memorialista; por isso mesmo é escrito com o uso da primeira pessoa."

\footnotetext{
${ }^{5}$ Os memoriais também estão sendo solicitados em processos seletivos em diferentes universidades - em nível de mestrado, bem como de doutoramento.
} 
Conforme Passegi (2008, p. 120), pode-se definir memorial enquanto,

[...] gênero acadêmico autobiográfico, por meio do qual o autor se (auto)avalia e tece reflexões críticas sobre seu percurso intelectual e profissional, em função de uma demanda institucional. O interesse de sua narrativa é clarificar experiências significativas para a sua formação e situar seus projetos atuais e futuros no processo de inserção acadêmica e ascensão profissional.

Reconhecemos a importância dos memoriais, a necessidade de reavaliar as trajetórias e, principalmente, as especificidades de seu principal componente, a memória. Referenciamos a memória como um campo de disputas e, sobretudo, como uma elaboração realizada no presente, o seu objeto, bem como os critérios de sua seletividade, sempre se encontrarão inseridos no atual movimento das relações sociais. Seguindo com Magalhães e Almeida (2011, p.103),

[...] a memória comparece como uma importante fonte de ligação entre o passado e o presente, ou seja, da racionalização temporalizada das experiências. Portanto, como toda fonte, pode estar ideologicamente formada, carecendo de ser analisada. Isto nos obriga a anunciar, embora não tenhamos condição de aqui adentrar na distinção entre História e Memória, que a história em sua autonomia, pode não coincidir necessariamente com a memória, ou seja, há de se pensar que nesta relação há sempre que se discutir o tema da "consciência".

Para além da questão das memórias, acerca da coleção de memoriais, estamos convencidos que faz-se necessário pontuar os catastróficos impactos da reestruturação produtiva, espraiados de forma sistemática nos diferentes campos da vida humana e que fincaram, de maneira contundente, a lógica do mercado nos processos educativos, sejam esses processos formais e/ou informais.

Peixoto (2020, p. 01), num escrito que é, praticamente, um retrato da condição dos trabalhadores da educação no Brasil, destaca que "[...] dos anos 70 para cá, o capital avança de forma mais agressiva sobre a educação tomada efetivamente como mercadoria com um valor de uso ${ }^{6}$ muito particular para os próprios capitalistas". Não à toa, Saviani (2013, p. 425), vai apontar a intensificação do neoprodutivismo e suas variantes: neoescolanovismo, neoconstrutivismo, neotecnicismo, a partir da década de 1990 no bojo de uma série de reformas neoliberais no campo da educação no Brasil.

\footnotetext{
${ }^{6}$ Grifos da autora.
} 
Desse modo, não poderia ser diferente no campo da formação de professores. Moraes (2004, p. 88), ao analisar o contexto da pós-graduação de professores no Brasil, reitera que faz-se necessário, com o objetivo de criar consenso para as mais variadas reformas educacionais no Brasil, a positivação “[...] de um novo vocabulário - suporte à criação de novos desenhos conceituais - que realiza a ressignificação de conceitos, categorias e termos" de forma a convertê-los, moldá-los aos "novos" paradigmas educacionais referenciados pelas reformas.

Na esteira da positivação destes novos vocabulários, chamamos atenção para a expressão ideológica que vai ganhando espaço, sobretudo, a partir das últimas décadas do século XX, isto é, o pós-modernismo ${ }^{7}$. Não empreenderemos um trato mais acurado acerca da questão, mas fazemos referência às tendências intelectuais e políticas que não se interessam em apreender os fenômenos a partir de suas determinações históricas, que se pautam nas narrativas, em percepções individuais e/ou de determinados grupos e que valendo-se de sensações emocionais, apreendem a linguagem, a cultura e os "discursos" como centro de suas análises.

Neste sentido, dialogamos com Duarte (2008, p.13-14),

Quando uma ilusão desempenha um papel na reprodução ideológica de uma sociedade, ela não deve ser tratada como algo inofensivo ou de pouca importância por aqueles que busquem a superação dessa sociedade. Ao contrário, é preciso compreender qual o papel desempenhado por uma ilusão na reprodução ideológica de uma formação societária específica, pois isso nos ajudará a criarmos formas de intervenção coletiva e organizada na lógica objetiva dessa formação societária.

Não é possível apreender a realidade negando ou secundarizando a centralidade das formas como os homens produzem e reproduzem a vida e/ou refutando a cisão existente entre classes sociais. Os mitos pós-modernos trazem consigo o ocultamento das determinações históricas e, de forma inequívoca, se consubstanciam com as reformas educacionais. Duarte (2008, p.14), acerca da vigência da sociedade capitalista e a necessidade de superá-la, chama atenção para a funcionalidade ideológica do pósmodernismo, ramificando-se na

\footnotetext{
${ }^{7}$ Utilizamos a expressão pós-modernismo e mais à frente pós-moderno sem distinções a fim de abarcar diversas correntes intelectuais e políticas que emergem a partir da segunda metade do século XX, entre elas o pós-marxismo e pós-estruturalismo. Reconhecemos diferenças entre essas correntes, mas optamos pela apreensão de Wood e Foster. Ver: Em defesa da história: Marxismo e pós-modernismo. Tradução: Ruy Jungmann, Rio de Janeiro, Jorge Zahar, 1999.
} 
[...] crença de que essa luta teria sido superada pela preocupação com outras questões "mais atuais", tais como a questão da ética na política e na vida cotidiana pela defesa dos direitos do cidadão e do consumidor, pela consciência ecológica, pelo respeito às diferenças sexuais, étnicas ou de qualquer outra natureza.

A proposição de Duarte (2008), sublinha uma das interseções mais evidentes da propagação do pós-modernismo no campo da educação em consonância com as atuais reformas educacionais neoliberais, isto é, a conformação dos indivíduos para a atual forma de sociabilidade. A fragmentação e/ou a parcialidade das análises, como nos memoriais, por exemplo, evidenciam apenas, a partir da cotidianidade das experiências, possibilidades de ajustamento aos indivíduos.

A ideologia pós-moderna, que se consolida com os pressupostos neoliberais, forja uma compreensão da realidade que está restrita a retalhos que não se combinam, segmentos que não possuem qualquer tipo de articulação. Todas as manifestações sociais são reduzidas a epifenômenos com o objetivo de descaracterizar qualquer possibilidade de compreensão da totalidade ${ }^{8}$. Desse modo, compreensões incompletas relativizam as possibilidades do conhecimento científico. À vista disto, concordamos com Wood (1999 p. 14-15):

Estruturas e causas foram substituídas por fragmentos e contingências. Não há um sistema social (como, por exemplo, o sistema capitalista), com unidade sistêmica e "leis dinâmicas" próprias; há apenas muitos e diferentes tipos de poder, opressão, identidade e "discurso". Temos que rejeitar não só antigas "histórias grandiosas", tal como os conceitos de progresso iluministas, mas também a noção de processo histórico e causalidades inteligíveis [...].

Na medida em que o ideário pós-moderno difunde o amoldamento à sociedade capitalista, relativiza a possibilidade de apreensão da realidade através do conhecimento e, com isso, pavimenta uma trilha para que seus ideólogos ${ }^{9}$ supervalorizem as experiências, isto é, as práticas ${ }^{10}$ em detrimento do conhecimento teórico, científico,

\footnotetext{
${ }^{8}$ Compreendemos o sentido de totalidade não enquanto a expressão de todos os fenômenos da humanidade, mas sim como "a realidade como um todo estruturado, dialético, no qual ou do qual um fato pode vir a ser racionalmente compreendido", tal como nos ensina Kosik. Ver: Dialética do Concreto

${ }^{9}$ Entre os ideólogos com bastante influência na formação de professores no Brasil, podemos citar: Tardif, Nóvoa, Perrenoud, entre outros.

${ }^{10}$ Para uma apreensão de prática que ultrapasse a assimilação vulgar e pragmática, recomendamos a obra de Elza Peixoto. Ver: Para a crítica dos fundamentos da formação de professores no Brasil: o problema da prática. Goiânia: Edições Gárgula; Editora Kelps, 2021.
} 
produzido sobretudo nas universidades públicas. A partir de suas parcas contribuições, estes ideólogos vêm constituindo, ao longo das últimas décadas, o pensamento pósmoderno como hegemônico dentro do campo da formação de professores.

A “epistemologia" da prática, em detrimento ao conhecimento sistematizado, ecoa como uma espécie de mantra na formação de professores. Campos e Pessoa (1998, p.195), sublinham que a "epistemologia" da prática "[...] não se refere especificamente à Formação de Professores, mas à formação de profissionais de áreas com características diferentes encontradas nos meios escolares". Entretanto, de acordo com Sousa (2018, p.39), “[...] essa teoria é transposta para o campo da Formação de Professores e trazida para o Brasil, na década de 1990, no momento da reforma educacional e de Reforma do Estado".

Quem nunca ouviu, na formação de professores, proposições que afirmavam ser característica das licenciaturas um grande aprofundamento teórico e uma prática diminuta? Em grande medida, para além de uma total incompreensão acerca do que é teoria, no máximo os indivíduos haviam lido alguns fragmentos e/ou capítulos de livros.

Nesse sentido, é a partir do espraiamento do pós-modernismo que versa com pressupostos irracionalistas, fundindo-se e confundindo-se com a agenda neoliberal que nos preocupa a hipostasia da experiência que, em boa medida, é incorporada nestes relatos. Dialogando com Santos Neto (2011, p.116),

[...] o empirismo se pauta por uma habitual "ternura pelas coisas do mundo". Essa posição tem o costume medular de cancelar os nexos contraditórios que perpassam a realidade. Fixada na postulação da sensibilidade como critério fundamental do conhecimento, a fetichização empirista não é capaz de compreender o movimento dialético que perpassa a relação entre fenômeno e essência, e acaba concedendo ao mundo da imediatez o caráter de verdadeira essencialidade.

O movimento dialético fundamental entre singular, particular e universal, esvaziase nas linhas e entrelinhas de comoventes histórias de vida. Moraes (2004, p. 90) é cirúrgica,

Uma vez perdida no passado a noção epistêmica do conhecimento, põese hoje, em seu lugar, o vulgar processo associativo de empirias compartilhadas, um "saber-fazer" que até pode ser criativo, mas sempre será fortemente restritivo, passivo na aceitação de todo o status quo, mesmo quando admite transgressões. Até porque, restritas ao nível do empírico, eventuais transgressões não têm como fugir do individual ou 
do grupo, uma vez que o mundo esgota-se nas impressões e sensações colhidas pelo sujeito ou pelo grupo.

A fim de não incorrer na direção de caminhos tortuosos, não nos arriscaremos na construção de um memorial. Porém, tentaremos ladrilhar algumas vias, de forma bastante introdutória, para pensarmos trajetórias no atual modelo de sociabilidade.

\section{Lugares-Comuns}

Antes de tentarmos elencar algumas trajetórias e dialogar com a pergunta que intitula o escrito, achamos relevante destacar algumas palavras que nos memoriais, bem como nos diferentes espaços de formação, ouvimos professores afirmarem com bastante frequência. Entre estas palavras, sublinhamos: privilégio, resiliência e resistência.

Vários professores, ao narrarem suas trajetórias, afirmaram de forma devotada que sentiam-se privilegiados por conseguirem chegar até determinado lugar, outros, com ares mais obstinados, chamavam a atenção para o quanto resilientes haviam sido e muitos nos contavam acerca das resistências empreendidas até ali, em grande medida, exemplificando uma determinada situação.

Seria mesmo privilegiado quem exerce o trabalho de professor? Ou alguém que consegue acessar a universidade, cursar uma pós-graduação? Eu acredito que sim, mas tão somente se rebaixarmos a nossa compreensão acerca do que venha a se constituir enquanto um direito. Stuchka (2001, p.74), nos diz que "o Direito é um sistema de (ou uma ordem) de relações sociais que corresponde aos interesses da classe dominante e que, por isso, é assegurado pelo seu poder organizado (o Estado)".

A proposição de Stuchka (2001) merece desdobramentos, sobretudo acerca do contínuo movimento contraditório característico de todos os processos, todavia, não o faremos aqui. O que importa compreender é que mesmo quando partimos das determinações das relações burguesas e de seu caráter de classe, a quem interessaria apreender direitos básicos, como o acesso à educação e/ou ao trabalho, enquanto privilégios? 
A palavra resiliência é lugar comum na formação de professores. Se consultarmos o dicionário ${ }^{11}$ encontramos algumas definições para a nossa palavra da moda, vejamos: "capacidade de quem se adapta às intempéries, às alterações ou aos infortúnios"; "propriedade dos corpos que voltam à sua forma original, depois de terem sofrido deformação ou choque"; "tendência natural para se recuperar ou superar com facilidade os problemas que aparecem". Parece-nos que resiliência, diferente de algumas expressões de "um novo vocabulário" que se alinha aos "novos" paradigmas educacionais, surge desnudada das alardeadas "ressignificações".

Desse modo, o caráter adaptativo se evidência de forma desavergonhada, isto é, compelir os indivíduos para os dissabores da atual forma de sociabilidade é a norma. Sem interdições e de forma capciosa, resiliência, está inserida entre as competências gerais da Educação Básica dispostas na Base Nacional Comum Curricular (BNCC) ${ }^{12}$.

Ora pois! Em virtude da graça dos privilégios, bem como, através de todo o nosso caráter adaptativo que emerge a partir da resiliência, só poderíamos ter chegado aqui por conta da nossa resistência. Quando nos deslocamos do sentido histórico, individualizamos ações e identificamos os processos a partir de um léxico neoliberal/pósmoderno, podemos enxergar resistência até no ato de amarrar os sapatos.

Contudo, no sentido de versar em alguma medida com a tarefa que nos foi posta, desejamos, a partir de breves linhas, apresentar algumas trajetórias de companheiros que estiveram conosco nos anos escolares, sobretudo no ensino médio. O critério para a escolha deste período, certamente, não se encontra relacionado apenas por uma maior proximidade temporal.

\section{Trajetórias}

Júlio $^{13}$ era um garoto comum, quando o conhecemos deveria ter entre 14 e 15 anos, muito popular na escola, estava sempre sorrindo e rodeado de amigos. Sempre cordial com todos, o seu desempenho escolar era satisfatório, passava nas disciplinas sem muitas dificuldades. Algumas vezes, ao final do período de aulas, o pai de Júlio passava na escola e o levava para casa.

\footnotetext{
${ }^{11}$ FERREIRA, Aurélio Buarque de Holanda. Dicionário da língua portuguesa. 5. ed. Curitiba: Positivo, 2010. 2222 p. ISBN 978-85-385-4198-1.

${ }^{12}$ Disponível em: http://basenacionalcomum.mec.gov.br/abase/\#introducao

${ }^{13}$ Os nomes Júlio, Lenice e Edmilson são fictícios
} 
No último ano do ensino médio, a presença de Júlio era cada vez mais esporádica, alguns colegas quando o avistavam na escola logo ressaltavam a casualidade do ocorrido. Ficamos sabendo, após algum período, que o seu pai tinha falecido, nunca soubemos detalhes e ele, dentro destas raras oportunidades em que se encontrava presente na escola, em nenhum momento comentou.

O jovem, após a morte do pai - provedor material da família - tinha arrumado um trabalho num açougue que ficava bem distante do bairro que residia. Comunicativo e sempre atencioso com todos, parecia, agora, como que "virado para dentro"14. Há anos não sabíamos do paradeiro de Júlio, até encontrarmos alguns contemporâneos do ensino médio que nos informou que ele havia acabado de sair, em liberdade condicional, do presídio, local onde passara quatro anos cumprindo pena por tráfico de drogas. A mãe de Júlio havia contraído alguma doença e o seu salário, como açougueiro, era insuficiente para custear o tratamento.

Lenice sempre foi uma aluna muito aplicada, não era muito comunicativa, passava maior parte do tempo entre o mesmo pequeno grupo de meninas. Sabíamos que a família da jovem era muito presente na escola e sempre se preocupava com o seu desempenho em relação as notas. O pai de Lenice era pastor em alguma igreja, destas que encontramos na mesma proporção que botequins.

A dedicada menina, após terminar o período do ensino médio havia prestado vestibular, queria ser professora. Tentou na universidade estadual, tentou, tentou na universidade federal, mas nunca atingiu o número mínimo de pontos para se classificar. Acompanhamos de perto essa peleja por três anos. O pai de Lenice tentou falar com o bispo de sua igreja, queria que ele intercedesse com uma bolsa numa universidade privada que pertencia ou pelo menos carregava o nome da mesma igreja na qual ele trabalhava. Não teve jeito!

No último ano em que tivemos contato, ela estava grávida. Há alguns meses namorava um rapaz do bairro, todos afirmavam que tratava-se de uma boa figura, trabalhador, todavia, o pai de nossa amiga não guardava muitas afinidades com o varão. Com a chegada da criança, a jovem e seu companheiro ficaram abrigados na casa dos pais da moça. Meses se passaram e por alguma desavença, com o pai de Lenice, foram postos

\footnotetext{
${ }^{14}$ Ver: IASI, Os homens sem plumas. Disponível em: https://blogdaboitempo.com.br/2020/11/27/oshomens-sem-plumas/
} 
para fora de casa. Lenice, hoje, trabalha junto com seu companheiro como vendedora ambulante no centro de Salvador, revende de água mineral até capas para celulares.

Mas a história de Edmilson foi diferente, quando ele terminou o ensino médio conseguiu logo um emprego, cobrador de ônibus. Não era bem o que ele queria, mas estava satisfeito por trabalhar, e ainda com o privilégio da carteira assinada. Edmilson, morava num bairro extremamente pobre de Salvador, o seu sonho mesmo era ser policial. Menino pobre, negro, morador de periferia, sabia o "poder" que um policial tinha na comunidade. Por inúmeras vezes já tinha sido abordado por policiais e, frequentemente, mencionava acerca da violência. Histórias de assassinatos, extorsões, estupros e as mais diferentes agressões cometidas pela polícia em seu bairro faziam parte de sua rotina.

Edmilson prestou vestibular, fez para o curso de direito, já estava em vigor o Exame Nacional do Ensino Médio (ENEM). Não conseguiu desempenho suficiente para o curso pleiteado, entretanto, com a pontuação obtida logrou o curso de licenciatura em história na Universidade Federal da Bahia (UFBA), mais uma vez, não era bem o que ele queria.

Mesmo ingressando no curso de licenciatura em história, Edmilson ainda guardava o desejo de trabalhar na polícia. Ponce (2007, p. 36), afirma que as classes opressoras estabeleceram, ao longo da história, em relação às oprimidas, “[...] uma consciência mais clara de si próprias”. Poderíamos nos ajustar à máxima freiriana e dizer que “[...] quando a educação não é libertadora, o sonho do oprimido é ser o opressor", mas, apesar de concordar em boa medida com Freire, ${ }^{15}$ é preciso buscar as unidades de contradições que movem o real.

Edmilson tinha uma família bastante numerosa, eram vários irmãos, lembro-me que a mãe havia falecido pouco tempo e o seu pai já tinha uma idade avançada. Em que profissão, sem nenhuma formação prévia sem nenhum tipo de qualificação, conseguiria um salário capaz de manter as necessidades básicas de sua família? E estabilidade e assistência médica?

Recordamos, certa feita, Edmilson afirmando que iria estar mais afastado da licenciatura em história, pois, o estado havia aberto um concurso para seleção de soldados

\footnotetext{
15 Ver: FREIRE, P. Pedagogia do oprimido. Rio de Janeiros/ São Paulo: Paz e Terra, 2018. Consideramos que o núcleo do pensamento freiriano encontra-se nesta obra.
} 
da polícia militar e esta seria sua grande chance. As poucas vezes que nos encontramos após o anúncio, ele relatou acerca dos treinos que estava empreendendo para enfrentar a prova de resistência física, segundo ele, essa seria a maior dificuldade.

Algum tempo depois, durante uma aula de História Moderna, soubemos da notícia da morte de Edmilson, ele havia desmaiado na pista de atletismo de um quartel da polícia militar durante os testes físicos e, após ser levado para um posto médico, não resistiu e faleceu. Pouco tempo depois fomos visitar a família de Edmilson, a sua casa ficava num local bem afastado do centro da cidade, da pequena janela da sala, a vista dava para o abandono.

No diálogo com uma de suas irmãs, ela nos disse que Edmilson no dia de sua morte havia saído muito cedo, sem se alimentar e que os testes físicos, apesar da solicitação do estado para que os candidatos chegassem antes de 07 horas da manhã, só foram realizados entre 12 e 13 horas, isto é, no horário em que o calor se intensifica, sobretudo no verão. A irmã, entre histórias e lágrimas, nos mostrou o local onde ele estudava, a cama que ele dormia e a arrumação caprichosa de uma caixa que lhe servia como guarda-roupas. O pai de Edmilson faleceu poucos meses depois da nossa visita e sua família - da forma como pode - luta por alguma reparação judicial.

\section{Considerações Finais}

Se partirmos do entendimento atribuído às palavras que destacamos, na seção anterior, utilizadas frequentemente no relato dos professores acerca de suas trajetórias, poderíamos dizer que, talvez, Júlio não tenha tido privilégios e que, possivelmente, faltou resiliência para Lenice e que Edmilson não tenha, empreendido assim, tanta resistência. Sabemos, de acordo com Marx e Engels (2007, p.47), que

as ideias da classe dominante são, em cada época, as ideias dominantes, isto é, a classe que é a força material dominante da sociedade é, ao mesmo tempo, sua força espiritual dominante. A classe que tem à sua disposição os meios da produção material dispõe também dos meios da produção espiritual, de modo que a ela estão submetidos aproximadamente ao mesmo tempo os pensamentos daqueles aos quais faltam os meios da produção espiritual. As ideias dominantes não são nada mais do que a expressão ideal a das relações materiais dominantes, são as relações materiais dominantes apreendidas como ideias; portanto, são a expressão das relações que fazem de uma classe a classe dominante, são as ideias de sua dominação. Os indivíduos que compõem a classe dominante possuem, entre outras coisas, também consciência e, por isso, pensam; na medida em que dominam como 
classe e determinam todo o âmbito de uma época histórica, é evidente que eles o fazem em toda a sua extensão, portanto, entre outras coisas, que eles dominam também como pensadores, como produtores de ideias, que regulam a produção e a distribuição das ideias de seu tempo; e, por conseguinte, que suas ideias são as ideias dominantes da época.

O conteúdo das palavras exemplificadas ao longo do texto, inseridos em determinados contextos, surge, a despeito de quem as profere, num invólucro ideológico, isto é, a partir da expressão ideal das atuais relações de produção. Desse modo, com a funcionalidade de ocultar determinações, transformando exceções enquanto regras, naturalizando a história e, principalmente, apresentando interesses particulares como universais.

Faz-se necessário rasgar os véus que encobrem as condições que permitem compreender direitos como privilégios, é essencial que os indivíduos não sejam submetidos às diferentes violências, tendo sempre que adaptar-se, isto é, sendo resilientes. E, principalmente, enquanto tomarmos resistência como uma ação circunscrita à individualidade, descolada de qualquer forma de organização coletiva que proporcione saltos qualitativos na vida dos trabalhadores, a maioria não terá chance de ser professor, bem como, todos nós continuaremos inseridos de forma subalterna no atual modelo de sociabilidade.

\section{REFERÊNCIAS}

CAMPOS, S.C.; PESSOA, V.I.F. Discutindo a formação de professoras e de professores com Donald Schön. In: GERALD, C.M.G.; FIORENINI, D.; PEREIRA, E.M.A (Org.). Cartografias do trabalho docente: professor (a) pesquisador (a). Campinas, SP: Mercado das Letras, 1998.

DUARTE, N. Sociedade do conhecimento ou sociedade das ilusões? $1^{\circ}$ ed. Campinas, SP: Autores Associados, 2008.

MAGALHÃES, L D. R.; ALMEIDA, J. R. M. Relações simbióticas entre memória, ideologia, história e educação. In: LOMBARDI, J. C; CASIMIRO, A. P. B e MAGALHÃES, L. D. R (Orgs.). História, memória e educação. Campinas - SP: Alínea, 2011

MARX, K.; ENGELS, F. A ideologia alemã. Tradução Rubens Enderle, Nélio Schneider e Luciano Cavini Martorano. São Paulo: Boitempo, 2007.

MORAES, M. C. M. de. Iluminismo às avessas como contexto da pós-graduação no Brasil. EDUCAÇÃO UNISINOS, Vol. 8 № 15 jul/dez, 2004, páginas 79 a 101. 
NETO, A. B. S. Teleologia e História. Germinal: Marxismo e Educação em Debate, Londrina, v. 3, n. 1, p. 115-127; fev. 2011.

OLIVEIRA, J. L. de. Texto acadêmico. Petrópolis/RJ: Vozes, 2005.

PASSEGGI, M. C. Memoriais: injunção institucional e sedução autobiográfica. In: PASSEGGI, Maria da Conceição; SOUZA, Elizeu Clementino (Org.) (Auto)Biografia: formação, territórios e saberes. São Paulo: Paulus; Natal: EDUFRN, 2008. p. 103-132.

PEIXOTO, E. M. Nunca foi "apenas" uma professora. HISTEDBR. Online, 2020. Disponível em: https://www.histedbr.fe.unicamp.br/colunas/artigos/8414 Acesso 07/07/2021.

PONCE, A. (2007). Educação e luta de classes. São Paulo: Cortez.

SAVIANI, D. História das ideias pedagógicas no Brasil. $4^{\circ}$ ed. Campinas, São Paulo: Autores Associados, 2013.

SOUSA, J.F.A. Referencial teórico e Formação de Professores: uma análise necessária. In: MATOS, N.D.M.; SOUSA, J.F.A.; SILVA, J.C. (Org.). Pedagogia histórico-crítica: revolução e formação de professores. Campinas, SP: Armazém do Ipê, 2018.

STUCHKA, P. Direito de classe e revolução socialista. São Paulo: Instituto José Luis e Rosa Sundermann, 2001.

WOOD, E. M.; FOSTER, J. B. (orgs.). Em defesa da história: Marxismo e pósmodernismo. Tradução: Ruy Jungmann, Rio de Janeiro, Jorge Zahar, 1999. 